\title{
MECANISMOS DE HUMOR VISUAL EN LA COMEDIA DE SITUACIÓN CÓMO CONOCÍA A VUESTRA MADRE
}

\author{
LAUra María Aliaga AguZA \\ aliagaaguza@hotmail.com
}

\begin{abstract}
Resumen
La comedia de situación se caracteriza por ser un formato audiovisual donde el efecto humorístico se crea a partir tanto de humor verbal, como situacional y visual. En este artículo se realiza un análisis práctico de los mecanismos que crean el humor visual en una comedia de situación, la sitcom estadounidense Cómo conocí a vuestra madre, con el objetivo de crear un patrón generalizable que se pueda extrapolar a otras series dentro de este género. Para ello, analizamos los casos de humor visual que aparecen en la segunda temporada de dicha serie, utilizando como base teórica los seis recursos de conocimiento que ofrece la Teoría General del Humor Verbal (TGHV) establecida por Attardo y Raskin en 1991. En primer lugar, explicamos los rasgos más característicos de la comedia de situación. En segundo lugar, señalamos qué entendemos por broma visual. Finalmente, nos centramos en los mecanismos lingüísticos que utilizados en los ejemplos seleccionados para nuestro análisis. Se trata de elementos extralingüísticos que producen el efecto cómico a través de marcas que nos ayudan a detectar el humor.
\end{abstract}

PALABRAS CLAVE: humor visual, comedia de situación.

\section{Introducción ${ }^{1}$}

Una de las características más sobresalientes de la comedia de situación o sitcom es la variedad de formas que posee para crear el efecto cómico, ya que encontramos tanto humor verbal, como visual y situacional. En este trabajo nos centraremos

${ }^{1}$ Este artículo se integra en el Proyecto I+D FFI2012-30941 «Innovaciones lingüísticas del humor: géneros textuales, identidad y enseñanza del español».

\begin{abstract}
The sitcom is an audiovisual genre that is characterized by the creation of humorous effects from verbal, visual and situational humor. In this paper we make a practical analysis of mechanisms used to create visual humor in a sitcom, specifically, in the sitcom How I met your mother. To do this, we analyze visual humor in the second season, using the six different knowledge resources which appear in General Theory Verbal Humor (GTVH), created by Attardo and Raskin in 1991. First, we will explain the most characteristic features of the sitcom. Next, we will point our definition of visual joke. Finally we will center on linguistic mechanisms used in the examples from the analysis. Those are extralinguistic elements that produce a humorous effect through marks that help us on finding humor.
\end{abstract}

KEYWORDS: Visual humor, sitcom. 
exclusivamente en el humor visual, que aparece en la comedia Cómo conocí a vuestra madre, concretamente en 23 bromas visuales que hemos encontrado en la segunda temporada de dicha serie, con el objetivo de obtener un patrón generalizable que se pueda extrapolar a otras series dentro de este género. El resto de formas de humor serán analizadas en investigaciones posteriores.

Para empezar, acercaremos al lector a nuestro objeto de estudio. Para ello, señalaremos los rasgos característicos del género donde se inserta nuestro corpus, esto es, la comedia de situación y ofreceremos una definición tanto de lo que entendemos por broma visual, como de los mecanismos que producen el efecto hilarante, para facilitar la comprensión del análisis práctico. A la hora de analizar los 23 ejemplos prácticos nos apoyaremos en la Teoría General del Humor Verbal que establecieron Attardo y Raskin en 1991. Pese a que las bromas visuales no se consideran humor verbal, nosotros seguiremos dicha teoría por dos motivos. En primer lugar, puesto que dichas bromas visuales se encuentran insertadas dentro de un género mayor donde predominan los elementos lingüísticos, esto es, la comedia de situación, que entraría dentro de la categoría humorous plot, with humorous central complication (Attardo 2008). En segundo lugar, ya que para analizar las bromas visuales se pueden aplicar los cinco primeros recursos de conocimiento que utiliza la Teoría General del Humor Verbal, sustituyendo el sexto y último, que es el lenguaje, por los mecanismos concretos que se utilizan en el humor visual: se trataría de elementos extralingüísticos que producen el efecto hilarante a través de marcas, como pueden ser la imagen y la kinesia, que veremos en el análisis práctico.

En las próximas líneas nos centraremos, por un lado, en explicar los rasgos característicos tanto de la comedia de situación como del humor visual; y, por otro, en los seis recursos de conocimiento en los que se basa la Teoría General del Humor Verbal $(T G H V)$ y los mecanismos humorísticos (\$2). A continuación, realizaremos la presentación del corpus seleccionado para este estudio (\$3). Posteriormente, analizaremos los mecanismos humorísticos utilizados en los ejemplos seleccionados $(\$ 4)$ para finalmente establecer las conclusiones pertinentes $(\$ 5)$.

\section{Aproximación al objeto de estudio: la comedia de situación y las bromas visuales}

En este apartado, en primer lugar, nos centraremos en los rasgos característicos de la comedia de situación $(\$ 2.1)$. En segundo lugar, explicaremos qué entendemos por humor visual (\$2.2). En tercer lugar, prestaremos atención al funcionamiento de los seis recursos de conocimiento por los que se explica el humor en la Teoría General del Humor Verbal (TGHV) (2.3). Por último, definiremos los mecanismos humorísticos que aplicaremos a nuestro corpus de estudio (\$2.4), con el fin de facilitar la comprensión de los ejemplos prácticos.

\subsection{Características generales de la comedia de situación}

La sitcom o comedia de situación nace en Estados Unidos en 1951 con la serie I Love Lucy. Esta comedia de situación sentó las bases de lo que hoy en día conocemos como 
sitcom, puesto que es un género que no ha sufrido muchas modificaciones en su formato inicial. En palabras de Álvarez Berciano (1999: 12): «Te quiero Lucy [...] fue determinante en los años cincuenta para el establecimiento de la sitcom como forma reina del género, prácticamente como hoy lo conocemos». Actualmente, hay en antena multitud de series de situación estadounidenses que continúan creando nuevos episodios; encontramos ejemplos como Two and a Half Men (doce temporadas), How I Met Your Mother (nueve temporadas) o The Big Bang Theory (siete temporadas).

A continuación, resumiremos los rasgos característicos de las comedias de situación. Para ello seguiremos a Grandío Pérez y Diego González (2009). Cada temporada de la serie está dividida en capítulos de breve duración, episodios de aproximadamente 22 minutos. Estos son cerrados, es decir, en cada capítulo se concluye la trama, aunque nos parece conveniente señalar que en ocasiones el final se queda abierto, puesto que prepara al espectador para el siguiente capítulo. Aparecen personajes estereotipados. Las grabaciones se realizan en un estudio interior con distintos decorados fijos, con público en directo y risas enlatadas. Los diálogos son cortos, vivos, agudos, muy elaborados y con gags visuales. Además, normalmente hay tres tramas por capítulo, siendo una de ellas la principal.

En cuanto a la estructura de cada capítulo encontramos cinco partes bien diferenciadas. Al inicio, antes de los títulos de crédito, aparece un teaser o hook (avance). Es una parte muy breve, que oscila entre uno y tres minutos, donde se muestra la trama principal. Después de los créditos aparece la primera parte del capítulo, donde se desarrollan las distintas tramas. Esta parte termina con un cliffhanger (suspense) que crea suspense antes de pasar a la publicidad. Posteriormente, se desarrolla la segunda parte, donde se cierran las distintas tramas y se resuelve el conflicto mostrado en el suspense, normalmente de forma humorística. Al final del capítulo hay un tag o cola que se trata de un chiste final.

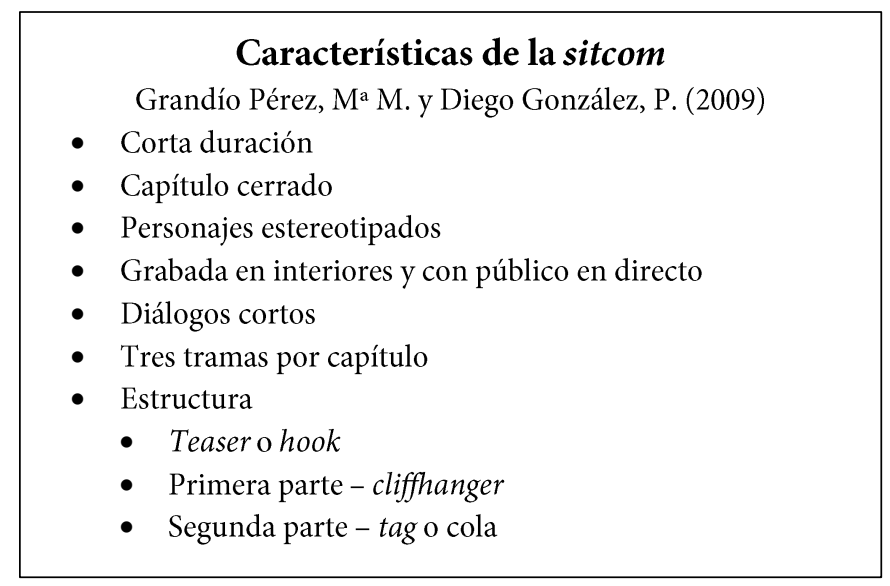

FIGURA 1: Características de la comedia de situación

Una vez comentados los aspectos más relevantes de la comedia de situación pasaremos a analizar los rasgos característicos de las bromas visuales. 


\section{2. ¿Qué es la broma visual?}

En las próximas líneas nos centraremos en especificar qué entendemos por humor visual, puesto que se trata de un término genérico que se produce a través de la imagen, ya sea fílmica o impresa. Para nosotros el humor visual corresponde al gag visual cinematográfico, esto es, el humor que se produce a través de la imagen en un medio audiovisual. No obstante, también es un término de difícil definición, ya que no hemos encontrado un consenso entre los distintos autores que hemos consultado. Según afirma Martín Peña (1991:18):

Aislado, el gag es un mecanismo indefinible que sirve para hacer reír.

Indefinible porque, en muchos años de teoría conocida, nadie ha podido rescatar con palabras la parte sensible del gag, visual o verbal que es la que lo vuelve eficaz. Cuando se procura edificar una definición que incluya eso, se obtienen resultados tan complicados que la esencia del gag, muy simple, deja de existir y las palabras se ahuecan.

Si recurrimos al Diccionario de la Real Academia Española ${ }^{2}$ obtenemos la siguiente definición: «gag: efecto cómico rápido e inesperado en un film o, por extensión, en otro tipo de espectáculo». Esta definición nos parece demasiado general por dos motivos; en primer lugar, porque se puede extrapolar a cualquier tipo de broma, ya sea visual, verbal o situacional. Y, en segundo lugar, puesto que no es exclusiva del medio audiovisual.

Por su parte, Bonet Mojica (2003: 15-16), tras revisar distintas definiciones de gag, llega a la siguiente conclusión:

[...] gag puede ser todo efecto, visual o verbal, que ligado a unas causas variables, cuya efectividad depende de la sensibilidad del espectador, motiva la risa. Resulta obvio señalar la superioridad del gag visual, por ser el cine el arte de la imagen. El gag verbal carece, en sí mismo, de plástica cinematográfica y, por otra parte, puede variar insospechadamente en el vertido de un idioma a otro.

En este sentido, consideramos importantes dos aspectos. En primer lugar, la importancia que Bonet Mojica le otorga al gag visual dentro del cine y, por consiguiente, del género audiovisual; en segundo lugar, la distinción que realiza entre el gag visual y el gag verbal, donde el primero se considera humor universal, mientras que el segundo es exclusivo de una lengua.

Seguiremos la definición que ofrece Cuéllar (1998: 73-74), puesto que, a nuestro parecer, se trata de la definición más abarcadora, la cual se puede extrapolar a otros géneros, es decir, Cuéllar considera el gag como un mecanismo más que ayuda a crear humor dentro de un género más amplio:

[...] aplicaremos el término de «gag» cinematográfico (o su equivalente castellano de «chiste fílmico») al mecanismo cómico desarrollado en una estructura dinámica, inserto en un relato mayor.

${ }^{2} 22^{\text {a }}$ Edición, versión on-line. 
Aplicamos el término «Mecanismo» en su acepción de medio prácticos empleados en las artes; "Cómico» en cuanto que dicho mecanismo es productor de comicidad; «Estructura dinámica» en su doble sentido: en cuanto que se desarrolla espacio-temporalmente (tiene una duración y sucede en un espacio) y en cuanto que no ofrece un modelo único, puede modificarse originando diferentes tipos; «Inserto en un relato mayor» porque, salvo que el «gag» constituya por sí solo un film, necesariamente el film ofrecerá un relato en el que va insertado un número indefinido de «gags».

De este modo, la comedia de situación recurre a la imagen como mecanismo para crear el efecto cómico junto a otros recursos como pueden ser lingüísticos, paralingüísticos, kinésicos o proxémicos. Sin dicha imagen no existiría humor, aunque nos parece conveniente señalar que, en ocasiones, va acompañada de algún comentario de los personajes que a pesar de no ser humorístico ayuda a crear el efecto hilarante. Por tanto, dentro del humor visual que encontramos en una comedia de situación se puede diferenciar entre broma visual como imagen, donde el humor se consigue simplemente a través de la imagen; broma visual como combinación de imagen y efecto sonoro, en este caso el sonido complementa el efecto humorístico; y broma visual como combinación de imagen y palabras, esto es, para que la imagen cree comicidad aparece un comentario de los personajes, ya sea para introducir la broma visual rompiendo las expectativas del espectador, ya sea para ampliar su efecto hilarante de forma posterior a la imagen.

\section{Tipos de humor visual}

Broma visual como imagen

Broma visual como combinación

de imagen y efecto sonoro

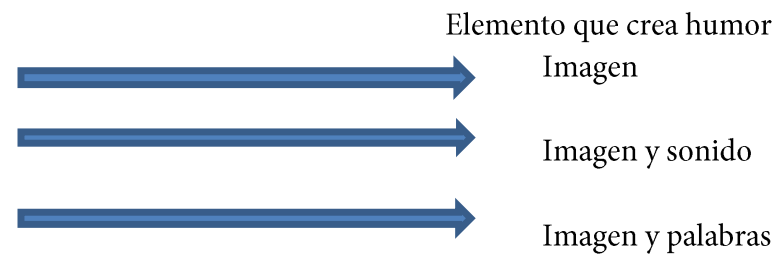

Broma visual como combinación de imagen y palabras

Imagen y palabras

FIGURA 2: Tipos de humor visual en una comedia de situación

En este estudio nos centraremos exclusivamente en el gag visual prototípico, esto es, en el humor creado a partir de la imagen sin otro soporte.

A continuación, trataremos los aspectos más relevantes de la Teoría General del Humor Verbal (TGHV).

\subsection{Teoría General del Humor Verbal (TGHV)}

Como hemos mencionado anteriormente, la Teoría General del Humor Verbaß explica el humor a partir de seis recursos de conocimiento. Estos seis recursos se aplican

\footnotetext{
${ }^{3}$ La Teoría General del Humor Verbal (TGHV) es una ampliación de la Semantic Script Theory of Humor (SSTH) establecida por Raskin en 1985. La SSTH fue la primera teoría que tiene en cuenta
} 
de manera jerarquizada. En primer lugar, encontramos la oposición de guiones que crean la situación humorística, es decir, para que un enunciado se considere humorístico deben existir dos marcos distintos y opuestos que creen ambigüedad y así se produzca el giro humorístico. En segundo lugar, aparece el mecanismo lógico, esto es, la manera en que el humor es detectado por el receptor. En esta fase se explica la incongruencia detectada anteriormente. A continuación, se debe tener en cuenta la situación donde se desencadena el chiste. Aquí se incluyen todos aquellos aspectos no humorísticos donde se produce la broma. Posteriormente, la meta u objetivo al que va dirigida la broma, es decir, el blanco del chiste ${ }^{4}$. Después, la estrategia narrativa, esto es, las características del género que se esté analizado. En nuestro caso, las características de la sitcom. Por último, el lenguaje, los elementos lingüísticos seleccionados. Sin embargo, en este artículo no tendremos en cuenta los elementos lingüísticos, puesto que los ejemplos visuales seleccionados se crean a partir de elementos extralingüísticos sin ningún apoyo sonoro ni verbal.

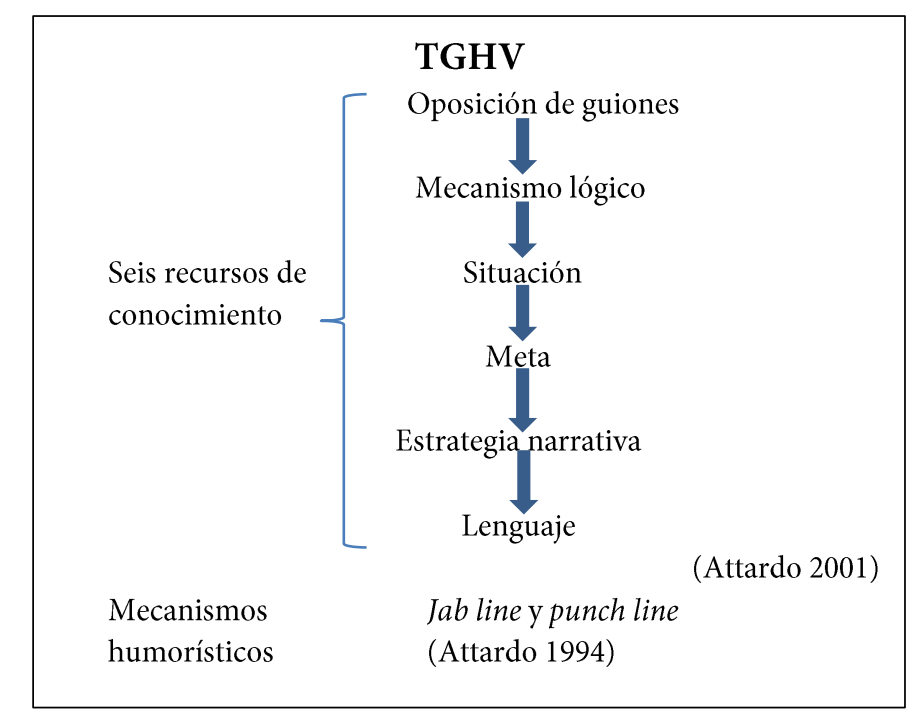

FIGURA 3: Disposición de los seis recursos de conocimiento de la $T G H V$

En el siguiente punto definiremos los mecanismos humorísticos que vamos a utilizar en el análisis de nuestro corpus.

tanto el componente semántico como el pragmático. Explica el humor a partir de dos afirmaciones: a) todo texto humorístico se puede interpretar a partir de dos guiones y b) dichos guiones tienen que ser opuestos.

${ }^{4}$ Nos parece conveniente señalar que en muchos de los casos que analizaremos en este artículo, $(\$ 4)$, no se da la meta, es decir, no aparece ningún personaje que sea el blanco de la broma, sino que simplemente es una situación cómica, puesto que se rompen las expectativas del espectador por medio de una incongruencia en la escena. 


\subsection{Mecanismos humorísticos}

En las próximas líneas nos centraremos en la terminología que utilizaremos en el análisis práctico con el fin de facilitar la comprensión de nuestro estudio.

Previamente al análisis realizado, hemos distinguido entre elemento lingüístico y elemento extralingüístico, donde elemento lingüístico corresponde a todo humor que se realiza con la palabra, mientras que elemento extralingüístico es el humor que se produce sin la intervención de la palabra. A su vez, dentro de cada elemento hemos establecido distintas marcas e indicadores que nos ayudan a la interpretación humorística. Siguiendo al grupo GRIALE ${ }^{5}$ (Ruiz Gurillo y Padilla García, 2009), entendemos por marca aquello que ayuda a crear el efecto humorístico, pero no es humorístico en sí mismo, mientras que indicador es aquella estructura humorística por sí misma.

Como hemos comentado anteriormente, en este trabajo nos hemos centrado en el humor visual que se produce exclusivamente a través de la imagen, donde no interviene la palabra. Por ello, en este apartado explicaremos las marcas que encontramos dentro de los elementos extralingüísticos.

La marca que más aparece en el humor visual es lo que hemos denominado marca visual. Dentro de la marca visual encontramos dos tipos: imagen y comparación de imágenes. En el primer caso, marca visual imagen, es la imagen en sí misma una estructura humorística, puesto que para que se produzca humor es necesaria dicha imagen. En el segundo caso, marca visual comparación de imágenes, el efecto humorístico aparece al equiparar la primera imagen con la segunda.

Otra marca que utilizamos para analizar el humor visual es la marca kinésica 6 . Dentro de ella encontramos cinco tipos. En primer lugar, marca kinésica gesto, donde el

\footnotetext{
${ }^{5}$ El Grupo GRIALE según se presenta en su página web, http://dfelg.ua.es/griale/index.html, es el Grupo de Investigación sobre la ironía y el humor en español del Ârea de Lengua Española del Departamento de Filología Española, Lingüística General y Teoría de la Literatura de la Universidad de Alicante. Fundado en 2002, ha contado hasta el momento con tres proyectos I+D, así como con diversas ayudas de la Universidad de Alicante. En el proyecto actualmente en vigor (FFI2012-30941: «Innovaciones lingüísticas del humor: géneros textuales, identidad y enseñanza del español») participan también dos miembros externos de reconocido prestigio: Salvatore Attardo, de la Texas A \& M University-Commerce (Estados Unidos) y Javier Muñoz-Basols, de la University of Oxford (Gran Bretaña). Sus objetivos principales son el análisis pragmático de la ironía y el humor, la observación de aspectos socioculturales, como la incidencia del género en su empleo, y la aplicación de los resultados a la clase de español como lengua extranjera. Destacan como publicaciones conjuntas el libro de Leonor Ruiz Gurillo y Xose A. Padilla (eds.) (2009): Dime cómo ironizas y te diré quién eres. Una aproximación pragmática a la ironía. Frankfurt, Peter Lang; el trabajo colectivo del grupo GRIALE (2011): ¿Estás de broma? 20 actividades para practicar la ironía en clase de ELE. Madrid, Edinumen; y la obra de Leonor Ruiz-Gurillo y Ma Belén Alvarado-Ortega (eds.) (2013): Irony and Humor: From Pragmatics to Discourse. Amsterdam, John Benjamins.

${ }^{6}$ Siguiendo a Poyatos (1994: 139) la kinésica «se puede definir como los movimientos y posiciones de base psicomuscular conscientes o inconscientes, aprendidos o somatogénicos, de percepción visual,
} 
humor se percibe visualmente a través de algún movimiento facial o corporal que realicen los personajes. En segundo lugar, tenemos marca kinésica manera, del mismo modo que la marca anterior, el humor se aprecia visualmente. Esta marca está relacionada con la forma de actuar de las personas, concretamente, cuando alguno de los personajes se comporta de forma no adecuada dentro de las normas sociales establecidas dentro de una comunidad. En tercer lugar, encontramos lo que hemos denominado marca kinésica caída, se trata de un mecanismo humorístico prototípico visual en el que la risa viene provocada por la caída de alguna persona. En cuarto lugar, hallamos marca kinésica reacción exagerada, en este caso el efecto cómico aparece cuando algún personaje reacciona de forma exagerada a los acontecimientos ocurridos y son percibidos por el espectador / receptor de forma visual. Por último, marca kinésica postura, donde el efecto hilarante aparece de forma visual a través de una posición corporal realizada por los personajes. Esta marca está relacionada con la marca kinésica gesto, puesto que ambas se realizan con el cuerpo, sin embargo se diferencian en que la marca kinésica gesto es un movimiento realizado con la cara o con las manos, mientras que la marca kinésica posición es una postura que adopta el cuerpo en un momento determinado.

La última marca que encontramos la hemos llamado marca idiosincrásica. Para entender el humor en este caso es necesario conocer la personalidad del personaje, puesto que es a través de ella cuando aparece el humor, es decir, se trata de un humor que no se aprecia hasta conocer los rasgos característicos de cada personaje.

La siguiente figura, 4, resume los mecanismos humorísticos que utilizaremos en el análisis práctico.

Una vez establecidas las bases teóricas para nuestro estudio ( $\$ 2)$ y antes de pasar a realizar el análisis práctico $(\$ 4)$, nos parece conveniente comentar las características de nuestro corpus $(\$ 3)$.

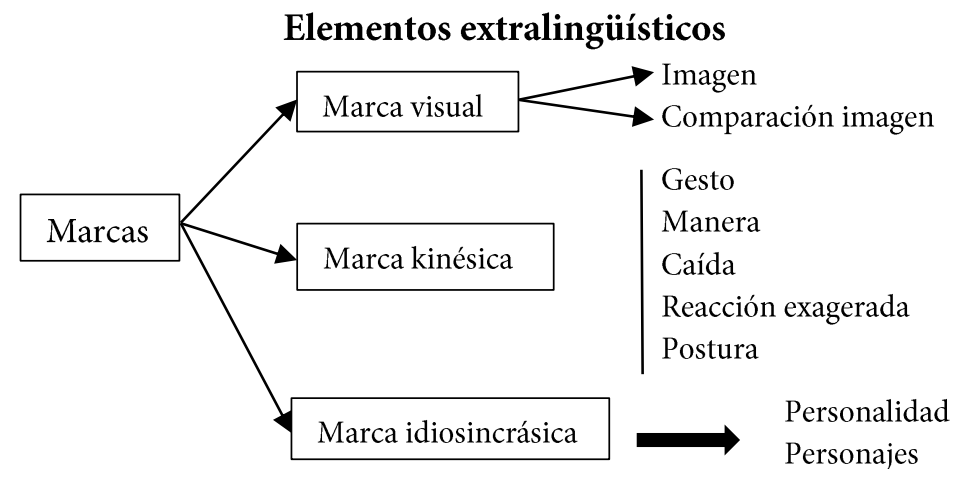

FIGURA 4: Marcas humorísticas de la broma visual

audiovisual y táctil o cinestésica que, aislados o combinados con la estructura lingüística y paralingüística y con otros sistemas somáticos y objetuales, poseen valor comunicativo intencionado o no». 


\section{Un corpus de comedia de situación: Cómo conocí a vuestra madre}

A la hora de caracterizar los mecanismos que se utilizan para crear humor a través de la imagen en una comedia de situación, hemos elegido la sitcom estadounidense Cómo conocí a vuestra madre, concretamente la segunda temporada, puesto que se trata de una comedia que lleva varios años emitiéndose y, además, va dirigida a un público general. Ha sido creada por Craig Thomas y Carter Bays y producida por la $\mathrm{CBS}^{7}$. Empezó a emitirse en el año 2005 y actualmente cuenta con nueve temporadas. La trama principal de la serie versa sobre la búsqueda de Ted Mosby de su mujer ideal y las aventuras que vive junto a sus amigos hasta encontrarla. En el año 2030, Ted Mosby (interpretado por Josh Radnor) relata a sus dos hijos cómo conoció a la madre de estos. La serie comienza en el año 2005, cuando los dos mejores amigos de Ted, Marshall Eriksen (Jason Segel) y Lily Aldrin (Alyson Hannigan), se prometen. Además de estos tres personajes, aparecen otros dos personajes principales como son Robin Scherbatsky (Cobie Smulders) y Barney Stinson (Neil Patrick Harris).

Antes de comenzar con la descripción del corpus (\$3.3), nos parece conveniente centrarnos en la caracterización de los personajes anteriormente citados $(\$ 3.1)$ y en el argumento de la segunda temporada de la serie $(\$ 3.2)$, puesto que pensamos que es necesario para la comprensión de las bromas visuales que analizaremos en el siguiente apartado $(\$ 4)$.

\subsection{Personajes de Cómo conocí a vuestra madre}

En este apartado nos centraremos en la descripción de los personajes principales de la serie que estamos analizando para facilitar la comprensión del humor visual que hemos seleccionado para este estudio, ya que en algunos casos el efecto cómico aparece a través de la personalidad del personaje.

Ted Mosby es el personaje principal de la serie. Es arquitecto, nació en Ohio y sueña con formar una familia junto a su mujer ideal, al igual que Marshall y Lily. Le apasiona la arquitectura y siente una pasión especial por el Empire State Building. Sus amigos le recriminan que piensa demasiado y que siempre está corrigiendo los errores de pronunciación y gramática que cometen los demás.

Marshall Eriksen es el mejor amigo de Ted desde que se conocieron en la universidad, y comparte apartamento con él en Nueva York. Nació en Minnesota y es abogado. Su sueño es trabajar en una empresa para proteger el medio ambiente, pero finalmente termina trabajando como asesor jurídico en un banco. Es una persona bonachona, pacífica y algo torpe. Es la pareja de Lily, de la que está enamorado desde que se conocieron en la universidad.

Lily Aldrin es la mujer de Marshall, la mejor amiga de Robin Scherbatsky, confesora de Barney Stinson y una de las mejores amigas junto a Robin de Ted Mosby. Es natural

\footnotetext{
${ }^{7}$ La serie se emite en la CBS estadounidense; en España en Antena 3 Neox y en Fox España; y, en Latinoamérica por el canal Fox Life.
} 
de Nueva York. Es profesora de jardín de infancia, aunque su sueño frustrado es ser pintora. Se caracteriza por ser muy cotilla, no poder guardar un secreto y ser experta en romper relaciones, sobre todo, las de Ted; además de tener una adicción oculta por la compra compulsiva de zapatos.

Barney Stinson es un personaje enigmático del que no tenemos mucha información, aunque a lo largo de la serie se van revelando sus secretos. Es un soltero empedernido al que le gusta tener relaciones esporádicas con chicas jóvenes y guapas. Trabaja como ejecutivo en las oficinas de un banco, aunque nunca se menciona a qué se dedica realmente. Siempre lleva traje debido a que en su juventud su novia le abandonó por un ejecutivo con traje y este hecho hizo que cambiase su concepción de la vida. Piensa que el traje es la mejor forma para ligar. Es un personaje manipulador, oportunista y tiene reglas sobre cómo conquistar a las mujeres. Tiene aprensión por las relaciones serias y el matrimonio y se considera el mejor amigo de Ted.

Robin Scherbatscky empieza a formar parte del grupo porque Ted quiere salir con ella. Es periodista y presenta el programa menos visto de Nueva York. Natural de Canadá, tiene discrepancias con algunas de las costumbres estadounidenses de sus amigos. Es un personaje independiente, al que no le gustan los niños ni el compromiso. Debido a que su padre la educó como si fuese un niño le apasionan las armas, los puros, el hockey y el buen whisky.

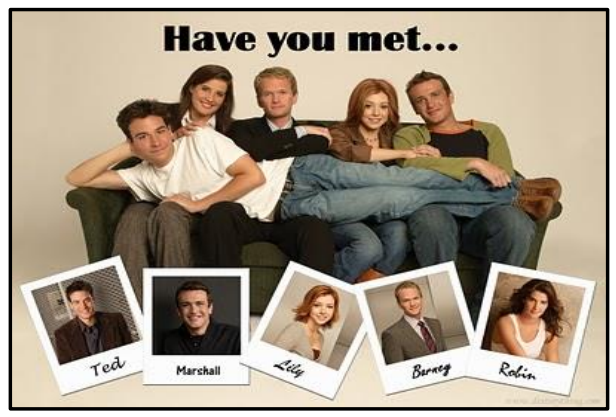

FIGURA 58: Personajes principales de Cómo conocí a vuestra madre

Una vez comentados los rasgos más sobresalientes de los personajes, pasaremos a relatar la sinopsis de la segunda temporada de la serie para situar al lector en la trama, esto es, en el contexto de las bromas que analizaremos posteriormente.

\subsection{Argumento segunda temporada de Cómo conocí a vuestra madre}

Para este estudio hemos analizado la segunda temporada de la serie estadounidense Cómo conocí a vuestra madre, compuesta de 22 capítulos, donde se relatan los acontecimientos que les ocurren a los cinco amigos a partir del verano de 2006. La temporada comienza en el momento en que Ted consigue empezar una relación seria

\footnotetext{
${ }^{8} \mathrm{La}$ imagen se puede encontrar en http://www.todofondosdeseries.com/category/como-conoci-avuestra-madre/page/2
} 
con Robin y con la ruptura del compromiso de Marshall y Lily, porque esta necesita desarrollar su faceta de artista en San Francisco antes de casarse. A lo largo de la segunda temporada vemos cómo evoluciona la vida de cada uno de los personajes en su nueva faceta. Marshall, una vez que se ha recuperado de la ruptura con Lily, comienza a salir con Barney para encontrar una nueva pareja, puesto que no sabe vivir sin compromiso. Por su parte, Lily vuelve a Nueva York tras su fracaso como artista y emprende su nueva vida sin Marshall. Tras varios intentos, Marshall tiene su primera cita seria y Lily hace todo lo posible para que fracase. Finalmente, Lily y Marshall comienzan de nuevo su relación y vuelven a comprometerse. En un primer momento, deciden fugarse a Atlantic City para casarse en secreto junto a sus tres amigos, porque Lily tiene miedo de la reacción de la familia de Marshall, aunque al final, deciden celebrar una boda tradicional. Durante este tiempo, Barney sigue aumentando la lista de sus conquistas amorosas, descubre que su hermano afroamericano y gay quiere casarse y que va a ser padre junto a su pareja homosexual, lo que le resulta muy difícil de afrontar por el rechazo que ambos mostraron siempre frente al compromiso. Por otra parte, también se desvela que Barney cree que su padre es el presentador de un famoso programa de televisión, aunque resulta no ser así. Por su parte, la relación de Ted y Robin es cada vez más seria, incluso se plantean vivir juntos. La temporada termina en mayo de 2007 con la boda de Lily y Marshall y con la ruptura de Ted y Robin, puesto que tienen intereses diferentes. De este modo, Barney volverá a tener a su compañero Ted para ligar.

A continuación, nos centraremos en los rasgos del corpus seleccionado para nuestro análisis.

\subsection{Corpus}

En este apartado señalaremos tanto las características generales de la segunda temporada de la comedia de situación estadounidense Cómo conocí a vuestra madre, como los ejemplos que forman nuestro corpus.

En primer lugar, nos parece conveniente señalar que esta serie cumple los rasgos característicos de este género ${ }^{9}$, esto es, cada capítulo dura 20 minutos y es cerrado. Hay 5 personajes estereotipados y risas enlatadas que se incluyen una vez que se ha grabado el episodio en el primer visionado de dicho capítulo. En cuanto a la estructura, cada capítulo se divide en avance, donde se introduce la trama. Después de los títulos de crédito, encontramos el desarrollo del capítulo separado por el suspense que ocurre justo antes de la publicidad. Por último, encontramos la cola o chiste final. Sin embargo,

\footnotetext{
${ }^{9}$ Según Grandío Pérez y Diego González (2009), las comedias de situación se dividen en capítulos que duran aproximadamente 22 minutos; cada capítulo cierra la trama, aunque en ocasiones el final prepara al espectador para el siguiente capítulo; posee personajes estereotipados; las grabaciones se realizan en platós, con público en directo y risas enlatadas; los diálogos son cortos, vivos, agudos, muy elaborados y con gags (chistes) visuales; suele haber tres tramas por capítulo, siendo una de ellas la principal. El capítulo se divide en teaser o hook (avance) que abre la trama, posteriormente el capítulo se divide en dos partes, separadas por el cliffhanger (suspense) que crea suspense antes de pasar a la publicidad, al final del capítulo hay un tag o cola que se trata de un chiste final.
} 
en ocasiones esta serie no incluye una cola final y no cierra el capítulo. En la temporada analizada esto ocurre en el primer capítulo donde vemos que Lily ha regresado a la ciudad, y en el último, que nos abre la trama para la siguiente temporada: Lily y Marshall van a emprender su vida de casados, mientras Ted y Robin han roto y Barney vuelve a tener a su compañero para salir a conquistar chicas. Además, este capítulo es especial, puesto que la estructura se divide en tres partes en lugar de dos como ocurre en el resto de episodios.

Como hemos comentado anteriormente, hemos analizado el humor visual que se crea a partir de la imagen, esto es, se trata de un humor que no contiene ningún elemento lingüístico ni sonoro para crear el efecto hilarante. En la segunda temporada de Cómo conocí a vuestra madre hemos encontrado 1417 casos de humor, ya sea verbal, situacional, visual o mezcla de alguno de ellos, basándonos en las risas encontradas. En cuanto al humor visual producido solo a través de la imagen encontramos 23 casos, lo que corresponde a un 1'6\%, un porcentaje muy bajo, puesto que hemos extraído exclusivamente el humor visual, aquel que no se mezcla con ningún otro elemento humorístico característico de la comedia de situación como puede ser el humor situacional o verbal. Se trata de un recurso que no se utiliza en todos los capítulos de la temporada, ya que solo lo encontramos en quince de ellos ${ }^{10}$. Además, nos parece conveniente señalar que se produce en todas las partes de los capítulos, esto es, aparece en dos ocasiones en el avance, en nueve ocasiones en la primera parte, en diez en la segunda y una en la cola. También, aparece un caso en la tercera parte del capítulo 22.

El humor visual está dirigido exclusivamente al espectador, puesto que los personajes de la serie no ríen tras la broma, pero sí podemos escuchar el conjunto de risas enlatadas. El efecto cómico, como veremos en el análisis práctico, se consigue a través de tres vías, esto es, 1) por medio de una imagen cómica incongruente dentro de la situación donde se enmarca; 2) a través de la puesta en escena de los personajes; $y, 3$ ) combinando tanto la puesta en escena como el carácter de los personajes.

A continuación, nos centraremos en el análisis de los procedimientos humorísticos que hemos encontrado en la segunda temporada de la comedia de situación Cómo conocí a vuestra madre $(\$ 4)$, con el fin de establecer una generalización de los mecanismos utilizados para crear humor visual en dicha serie (\$5).

\section{Análisis del humor visual en Cómo conocí a vuestra madre}

En este apartado analizaremos los mecanismos humorísticos utilizados para crear humor visual en la comedia de situación Cómo conocí a vuestra madre, esto es, nos centraremos en las escenas donde el humor viene determinado a través de la imagen sin recurrir a la palabra, ya sea por un escenario no previsible o por la puesta en escena por parte de los personajes. En primer lugar, estudiaremos los casos donde el humor se crea exclusivamente a partir de la imagen incongruente dentro de la situación donde se

\footnotetext{
${ }^{10} \mathrm{El}$ humor exclusivamente visual sin tener ningún soporte sonoro ni lingüístico lo hemos encontrado en los capítulos uno, tres, cinco, siete, ocho, nueve, trece, catorce, quince, dieciséis, diecisiete, diecinueve, veinte, veintiuno y veintidós.
} 
encuentran los personajes, esto es, es la imagen la encargada de romper las expectativas del espectador dentro de la situación generada en la escena $(\$ 4.1)$; en segundo lugar, examinaremos los ejemplos en los que el humor aparece a través de la puesta en escena, es decir, por medio de las marcas kinésicas (faciales o corporales) que realizan los personajes $(\$ 4.2)$; en tercer lugar, observaremos los casos donde el humor aparece al combinar la actuación de los personajes junto a un rasgo característico de la personalidad de estos $(\$ 4.3)$; por último, prestaremos atención a dos casos especiales que simulan una escena de cine clásico mudo (\$4.4). A la hora de ordenar los ejemplos en cada epígrafe nos basaremos en el efecto humorístico, es decir, agruparemos cada epígrafe según las tres vías por las que se genera el humor.

Como hemos indicado en la introducción, a la hora de explicar los ejemplos analizados seguiremos cinco de los recursos de conocimiento de la $T G H V$, puesto que el sexto, el lenguaje, lo hemos sustituido por mecanismos visuales. Para ello seguiremos el siguiente procedimiento: en primer lugar explicaremos la situación (recurso 3), para que el lector se sitúe en la trama donde se genera el humor. En segundo lugar, explicaremos tanto la oposición de guiones (recurso 1) como el mecanismo lógico (recurso 2). Posteriormente, nos centraremos en las marcas que ayudan a crear el efecto cómico. Por último, señalaremos la meta (recurso 4) en los casos en los que haya un personaje en el que recaiga la burla directamente y no se trate simplemente de una situación incongruente dentro de las expectativas creadas por el espectador. Nos parece conveniente señalar que el quinto recurso, la estrategia narrativa, es utilizado, a pesar de no ser explicado de forma independiente en cada caso, puesto que se trata de la estructura de cada capítulo (ver $\$ 2.1$ ) y nosotros hemos extraído ejemplos de distintos capítulos. Aun así es un aspecto que hemos tratado en distintas comunicaciones y en Aliaga Aguza (2013).

\subsection{Humor visual a partir de una imagen incongruente}

Para comenzar con el análisis de los casos de humor visual de la segunda temporada de la comedia de situación Cómo conocí a vuestra madre, en primer lugar, nos centraremos en los ejemplos que crean el efecto hilarante a partir de una imagen incongruente que rompe las expectativas del espectador generadas para la situación donde se inserta dicha imagen. Encontramos nueve casos, uno en el avance, tres en la primera parte del capítulo, cuatro en la segunda parte del capítulo y uno en la tercera parte del capítulo $22^{11}$. No encontramos ningún caso en la cola.

El único ejemplo que encontramos en el avance se halla en el capítulo 5, en el que Ted nos introduce el capítulo, se encuentran Ted y Robin visitando el nuevo apartamento de Lily, que se trata de un apartamento excesivamente pequeño que comparte habitación, cocina y baño. Aparece una cama plegable y Ted se prepara para bajar la cama. Ante esta situación, vemos como Lily pone escusas para que no la baje,

\footnotetext{
${ }^{11}$ Nos parece conveniente recordar que se trata del único capítulo de la temporada que se divide en tres partes.
} 
como vemos en (1) y a continuación se nos muestra la imagen que crea el efecto cómico ${ }^{12}$.

(1) T: oye cómo mola la cama plegable

L: sí está un poco desastrosa, esta mañana no he hecho la cama así que...

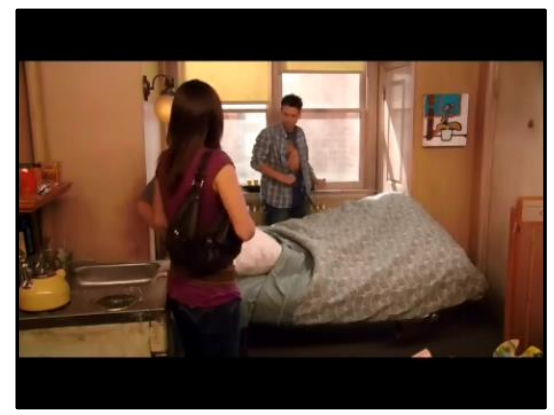

IMAGEN 1: La cama de Lily no cabe en el apartamento.

La oposición de guiones en este caso es cama deshecha / espacio pequeño. El mecanismo lógico es la imagen, puesto que el efecto cómico aparece cuando Ted baja la cama y no cabe entera en el apartamento. A partir de la marca visual imagen se ha roto la expectativa que se había creado el espectador, ya que le han hecho pensar que iba a encontrar una cama sin hacer $y$, en realidad, lo que vemos es una cama hecha, pero que no es posible desplegar completamente en el apartamento.

Como hemos mencionado anteriormente, hemos encontrado tres casos de humor visual en la primera parte de los capítulos. La primera la encontramos en el capítulo 1 donde, como ocurre en el caso anterior, la imagen rompe las expectativas que se ha creado el espectador a partir de la escena anterior a la imagen. En este caso nos encontramos en el verano de 2006 cuando Lily ha roto su compromiso con Marshall y se ha marchado a San Francisco para realizar un curso de arte. Marshall lo está pasando muy mal y sus amigos intentan que supere la ruptura. Acaba de recibir una carta con la factura de los movimientos de la tarjeta de Lily, en ese momento, Ted se la quita, la rompe, la tira a la basura y vemos cómo se marcha de casa con la basura en la mano para tirarla al contenedor. La siguiente escena (2) comienza con la imagen de la factura pegada en las manos de Marshall.

12 Para la transcripción hemos seguido el sistema del grupo de investigación Val.Es.Co para la Conversación Coloquial. http://www.valesco.es/sistema.pdf 
(2)

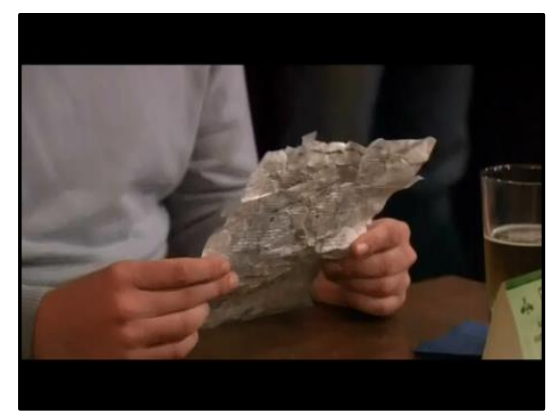

IMAGEN 2: Marshall con la factura reconstruida de los movimientos de la tarjeta de Lily en la mano.

En este caso la oposición de guiones es factura rota / factura reconstruida. Al igual que ocurre en el caso anterior el mecanismo lógico es la imagen, ya que el espectador no se espera encontrar a Marshall con la factura. Por tanto, la marca utilizada, como ocurre en el caso anterior es la marca visual imagen.

Otra imagen que crea el efecto cómico a partir de la ruptura de expectativas la encontramos en la tercera parte del capítulo 22. Lily y Marshall se acaban de casar. En el banquete prácticamente no han podido comer puesto que los invitados les interrumpían cuando tenían el plato de comida delante. Están montados en la limusina y le piden un favor al chófer. En la escena siguiente (3) vemos a los dos personajes vestidos de novios entrando en un restaurante de comida rápida.

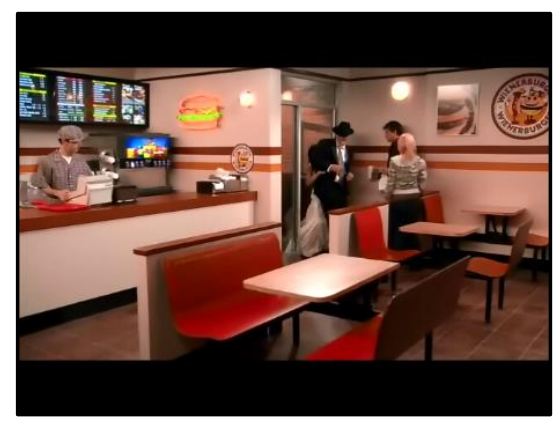

IMAGEN 3: Marshall y Lily entrando en un restaurante de comida rápida tras salir del banquete de su boda.

En el ejemplo (3) la oposición de guiones la encontramos en noche de bodas / cena en un restaurante de comida rápida. El mecanismo lógico también se detecta a través de la imagen, porque entre los distintos favores que pueden pedir los novios al chófer se encuentra el de ir a comer después del banquete de boda. En este caso, la marca que ayuda a generar el efecto humorístico es la marca visual imagen que rompe las expectativas creadas en la escena anterior. 
Otro mecanismo humorístico que se crea a partir de la imagen es la imagen en sí, una imagen que produce comicidad por sí misma en el conjunto de la escena, debido a que rompe las expectativas creadas por los personajes, como podemos ver en los ejemplos (4), (5) y (6)

(4)

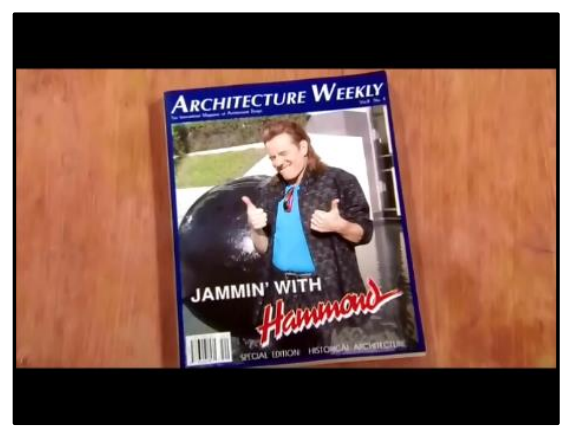

IMAGEN 4: Draders en los años 80

(5)

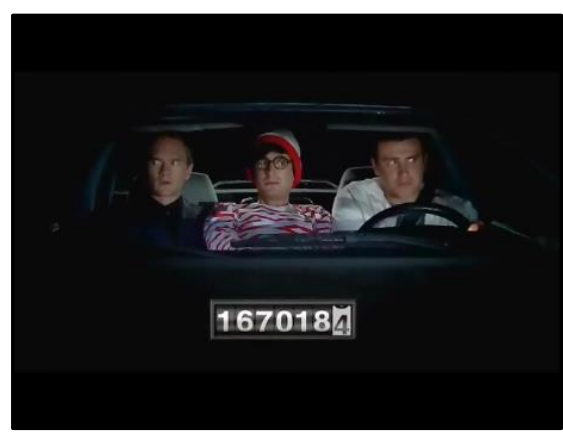

IMAGEN 5: Wally en el coche con Barney y Marshall

(6)

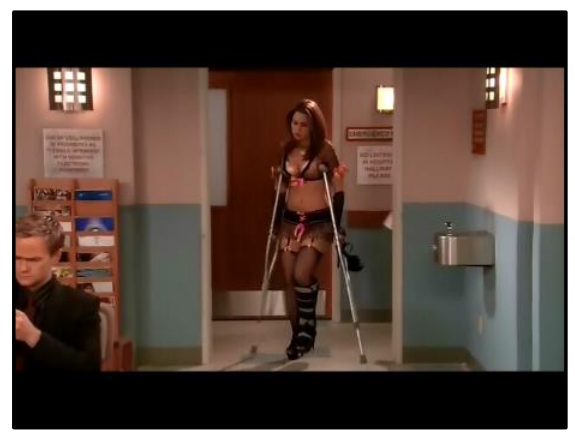

IMAGEN 6: La stripper con muletas

En (4), (5) y (6) el humor aparece a través de lo mostrado en la imagen, ya que es incongruente con lo esperado. En (4), primera parte del capítulo 13, Ted nos está 
explicando quién es Draders, un arquitecto de prestigio desde los años 80. A continuación aparece la portada de una revista donde la incongruencia se produce al ver a una persona importante y de gran prestigio vestida de esa manera. La oposición de guiones es persona formal/ persona informal. El mecanismo lógico es la imagen en sí misma, porque lo que se espera es ver a un personaje trajeado y no lo que se ve en (4), de ahí que la marca sea la marca visual imagen. En este caso la meta de la burla es Draders. En (5), segunda parte del capítulo 17, Marshall está recordando las experiencias que ha vivido con su coche, puesto que se ha quedado parado en medio de la calle y se encuentran todos en la sala de espera del taller esperando el pronóstico ${ }^{13}$. El efecto hilarante lo encontramos a través de la imagen, Marshall acaba de señalar que recogieron a un chico que estaba haciendo autostop en la carretera, en la siguiente escena se ve a un chico vestido de Wally entre Barney y Marshall, a esto hay que añadir la cara de circunstancia que tienen todos. La oposición de guiones es nombre / disfraz. Se repite el mismo mecanismo lógico que en los casos anteriores, la imagen, puesto que lo que crea humor es ver a Wally entre los dos personajes. La marca utilizada es marca visual imagen. Por último, en (6), segunda parte del capítulo 19, se encuentran todos los chicos en la despedida de soltero de Marshall. Pese a que ninguno de ellos quería el espectáculo de una stripper, Barney la contrata sin que ninguno se entere. Finalmente, los amigos aceptan ver el espectáculo antes de realizar el resto de actividades que tenían programadas, pero la stripper se lesiona y tienen que llevarla al hospital. El efecto cómico lo encontramos a través de la imagen cuando aparece la chica casi desnuda y con las muletas. La oposición de guiones es ropa de calle / ropa interior. El mecanismo lógico la imagen donde vemos a la stripper con su ropa de trabajo y la marca utilizada la marca visual imagen.

Por último, en (7), ejemplo perteneciente a la segunda parte del capítulo 14, encontramos el efecto cómico expresado solamente a través de la imagen. Es el día siguiente a la Super Bowl, pero los chicos no han podido ver el partido porque han tenido que asistir a un funeral, por lo que deciden grabarlo y verlo al día siguiente sin enterarse del resultado. Todos los años mientras ven el partido comen alitas de pollo de un bar que está al otro lado de la ciudad. Ted es el encargado de ir a recogerlas, pero como no quiere conocer el resultado del partido antes de verlo con sus amigos, decide fabricarse un «aislante sensorial 5000» (Imagen 7) con el que no puede escuchar nada y apenas ve (Imagen 8). Cuando llega al bar se encuentra con una chica con un escote muy pronunciado. En (7) el humor aparece cuando retrocede para volver a mirarle el escote, cuando lo que se supone que quiere es no ver nada (Imagen 9). Esta broma se vuelve a repetir unos minutos después, puesto que Ted llega a casa con las alitas de pollo y se da cuenta de que le falta la salsa; por lo tanto, tiene que volver al bar y al llegar se vuelve a encontrar con la chica y realiza la misma acción (Imagen 9). La oposición de guiones es recoger alitas / entretenerse en mirar escote. El mecanismo lógico es la imagen, la acción de retroceder para poder mirar el escote a una chica, además, el efecto

\footnotetext{
${ }^{13}$ Nos parece conveniente señalar que en este capítulo encontramos una personificación del coche, donde aparece un símil entre una persona enferma a punto de morir, donde los familiares recuerdan todas sus buenas hazañas y el coche.
} 
cómico aumenta cuando la escena se vuelve a repetir. La marca que se usa en este caso para generar humor es la marca visual imagen.

(7)

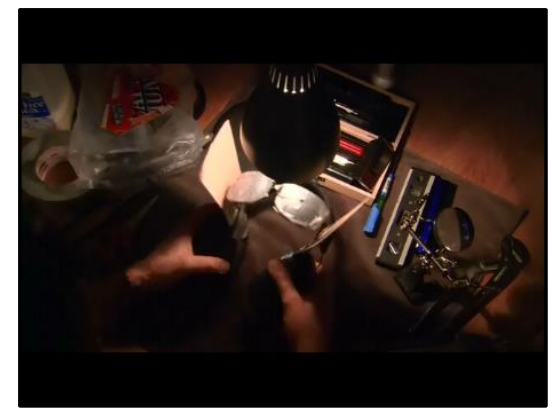

IMAGEN 7: Aislante sensorial 5000

(8)

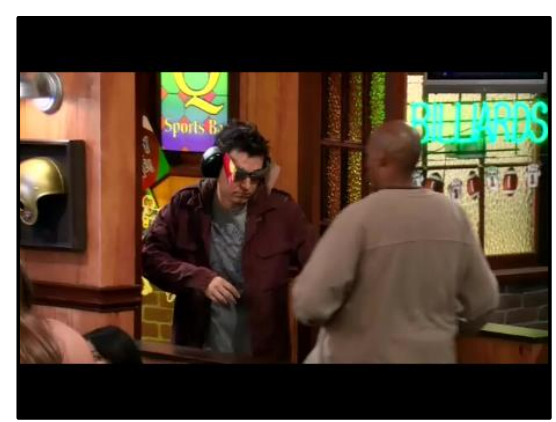

IMAGEN 8: Ted con el aislante sensorial entrando al bar deportivo

(9)

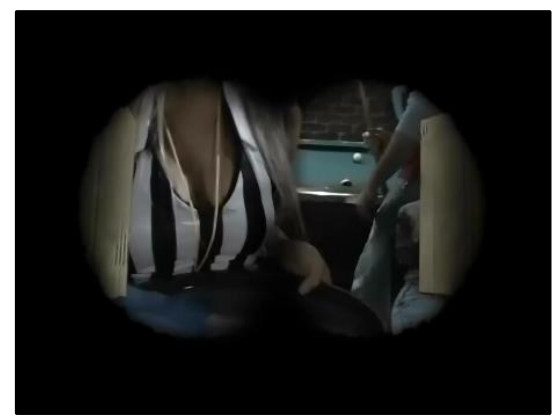

IMAGEN 9: Ted mirando los pechos de una chica

Por tanto, tras haber analizado el humor visual a partir de una imagen a través de los ejemplos seleccionados podemos señalar que la marca utilizada para su creación es la marca visual imagen, bien por medio de la imagen incongruente en sí misma, bien por la ruptura de las expectativas que se han creado o debido a la acción que se desarrolla. 
A continuación pasaremos a analizar el humor visual que se consigue a través de la incongruencia que genera algún aspecto kinésico de la actuación de los personajes.

\subsection{Humor visual donde la kinésica de los personajes crea la incongruencia}

En este apartado nos centraremos en el humor visual donde el efecto cómico se crea a partir de la puesta en escena de los personajes. Se trata del recurso más utilizado puesto que encontramos once casos. Uno en el avance, cuatro en la primera parte del capítulo y seis en la segunda parte del capítulo. No se ha encontrado ninguno ni en la cola ni en la tercera parte del capítulo 22.

La primera marca humorística que analizaremos es la imagen junto a la marca kinésica de manera, donde los personajes muestran un comportamiento no adecuado respecto a las normas sociales establecidas dentro de una comunidad. Este recurso lo encontramos en la primera parte del capítulo 19, (8), donde vemos a Robin cambiar las tarjetas de los regalos.

En (8) es la despedida de soltera de Lily, Barney ha convencido a Robin para que le regale a Lily en su fiesta de despedida un consolador. Cuando Robin llega a la fiesta, descubre que hay gente mayor y niños. Robin ha intentado marcharse en varias ocasiones, pero no ha podido. En un momento de desesperación, Robin se da cuenta que hay otro regalo con el mismo envoltorio que el suyo, por lo que decide cambiar las tarjetas de los regalos como vemos en la imagen 10 .

(10)

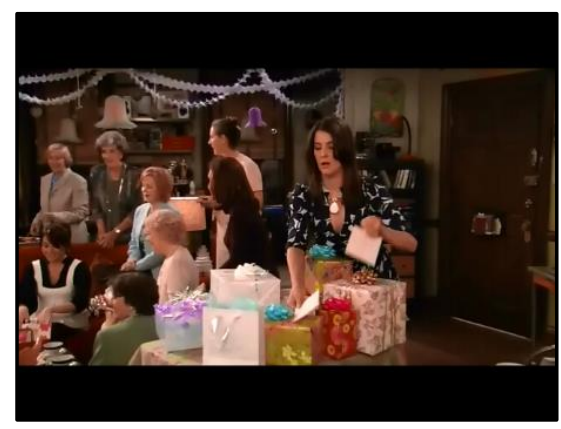

IMAGEN 10: Robin cambiando las tarjetas de los regalos

La oposición de guiones consiste en decir la verdad / mentir. El mecanismo lógico lo encontramos a partir de la imagen por medio de la actuación de Robin, ya que antes de asumir su actuación, decide cambiar las tarjetas sin pensar que finalmente se va a descubrir quién ha realizado ese regalo. Por tanto, la marca utilizada es la marca kinésica manera, puesto que Robin no ha actuado como establecen las normas sociales.

A continuación, nos centraremos en la marca más utilizada dentro de este tipo de humor, esto es, la marca kinésica facial. Hallamos tres casos, todos ellos en la segunda parte. El primero (9) en el capítulo 19, la cara que pone Robin en la despedida de soltera de Lily cuando la prima de esta le va a dar el regalo de Robin. El segundo (10) en el capítulo 7, donde Lily lanza una mirada a Robin porque está disgustada. Y el tercero 
(11) en el capítulo 21, los gestos que hace Marshall cuando se está probando un bisoñé después de haberse rapado la mitad de la cabeza el día de su boda.

En (9) la situación se desarrolla a partir de lo explicado en (8), Robin sigue preocupada por el regalo que ha llevado y ha cambiado las tarjetas con otro regalo. Lily está abriendo los regalos que le va acercando su prima Margaret. Margaret coge el regalo de Robin.

(11)

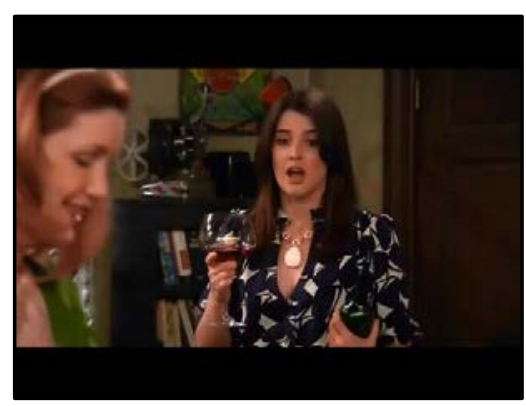

IMAGEN 11: Cara de Robin cuando cogen su regalo

La oposición de guiones se repite decir la verdad / mentir. El mecanismo lógico aparece por medio de la imagen y el gesto de Robin, cuando esta cambia su expresión al ver que Margaret ha cogido su regalo y se va a descubrir lo que ha llevado a la fiesta. A esto se le puede añadir el hecho de que se bebe la copa que tiene en la mano de un trago al ver que su regalo es el siguiente. En este caso la marca utilizada es la marca kinésica gesto.

La situación donde se desarrolla (10) es en el bar donde se encuentran Robin y Lily. Lily le pregunta por qué no la llamó la noche anterior para hablar sobre Marshall y la chica con la que está saliendo.

(12) $R$ : dijiste que no te importaba

L: ya, delante de Ted, pero luego te lancé una mirada

R: ¿qué mirada?

L: esta

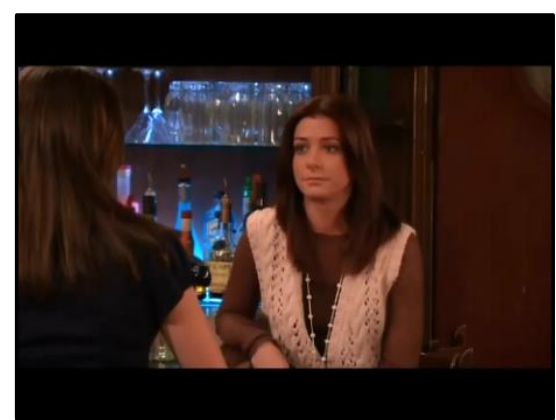

IMAGEN 12: Mirada que lanza Lily a Robin para mostrar su disgusto. 
La oposición de guiones en este caso es expresividad / inexpresividad. El mecanismo lógico se detecta a través de la imagen y el gesto inexpresivo de Lily, puesto que el efecto humorístico lo hallamos a través de la evidente inexpresividad de Lily cuando se supone que está haciendo un gesto claro que expresa su disgusto y su necesidad de hablar con Robin a solas. Por tanto, la marca utilizada es marca kinésica gesto.

En (11) es la boda de Marshall y Lily. La prima de Lily le ha hecho mechas a Marshall en el pelo. En un momento de desesperación Marshall ha cogido la máquina de cortar el pelo y se ha rapado una parte de la cabeza. Para solucionar el problema Barney y Ted le han robado a un invitado un bisoñé del mismo color del pelo de Marshall.

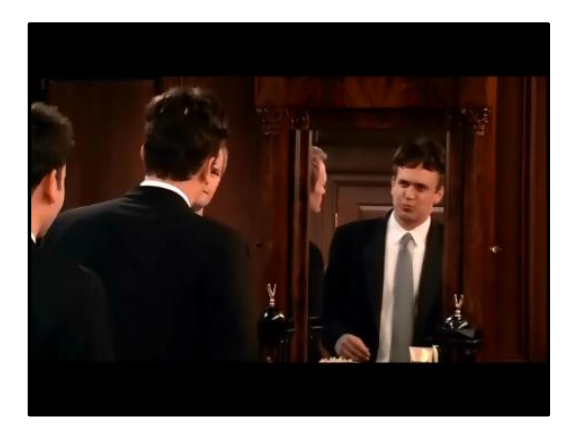

IMAGEN 13: Cara de Marshall al probarse el bisoñé

La oposición de guiones es natural / artificial y el mecanismo lógico aparece a través de la imagen, en la que vemos a Marshall con el bisoñé en la cabeza, resultando evidente la artificialidad del pelo y lo inadecuado de este para la situación. A esto hay que sumarle los gestos que realiza ante el espejo para verse más guapo, utilizando así la marca kinésica gesto para crear el efecto hilarante. En este caso el blanco de la broma es Marshall.

También encontramos otro caso (12) en la segunda parte del capítulo 14 donde se mezclan los mismos recursos que en los casos anteriores, junto a la marca kinésica de manera. Marshall ha ido a hablar a la clase de Lily el día después de la Super Bowl. Ninguno de los personajes ha podido ver el partido, puesto que tuvieron que asistir a un funeral. Todos han decidido no enterarse del resultado hasta que vean juntos el partido esa tarde después de trabajar. En la clase de Lily hay un niño que está chantajeando a Marshall porque sabe quién ganó el partido. El niño ha tirado una cosa al suelo y se rompe. Marshall asume la responsabilidad y Lily se ve obligada a aplicarle el mismo castigo que a los niños de su clase cuando se portan mal. 
(14)

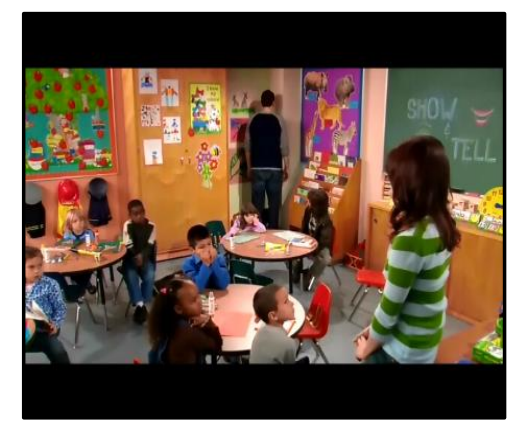

IMAGEN 14: Marshall castigado

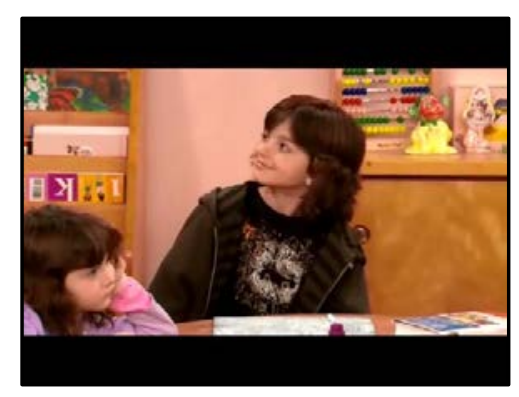

IMAGEN 15: Niño con gesto de satisfacción

La oposición de guiones viene dado por adulto / niño. El mecanismo lógico es la imagen y el gesto, en (12) la escena humorística se divide en dos, en primer lugar a través de la marca kinésica de manera donde observamos a Marshall -un adultocastigado de cara a la pared como si fuese un niño. En segundo lugar, la escena se cierra con la marca kinésica gesto a través del gesto de aprobación que realiza el niño tras conseguir sus objetivos.

Otro mecanismo para generar humor visual es la mezcla de marca kinésica manera y marca kinésica gesto corporal, concretamente, con las manos. En este caso encontramos un ejemplo (13) en el avance del capítulo 3, en el que la madre de Ted levanta las manos y tira la bandeja de una camarera. Además, este se repite a lo largo del capítulo para dividir el mismo en tres para relatarnos cómo fue el día para cada personaje.

En (13) Ted nos está introduciendo el capítulo, en el que están todos en un almuerzo y se hacen una foto de grupo en la que están todos sonriendo. A continuación vemos que en realidad todos están hablando por parejas y discutiendo entre sí. La madre de Ted está sentada al lado de Robin y esta quiere decirle a Ted algo que le acaba de decir su madre. En ese momento, la madre de Ted levanta las manos y tira la bandeja y a la camarera que está pasando por detrás de ella. 
(16)

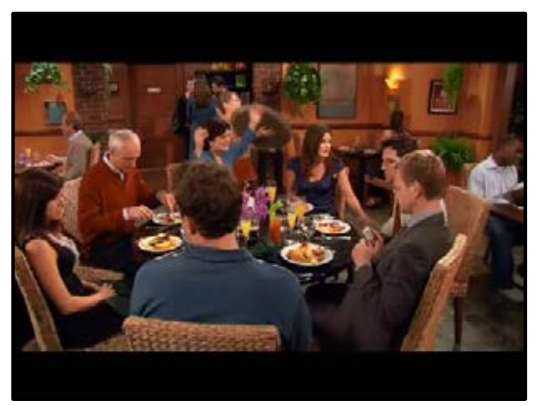

IMAGEN 16: Madre de Ted tirando la bandeja de la camarera

En esta ocasión la oposición de guiones es formal / informal, el mecanismo lógico es la imagen que nos muestra el comportamiento inadecuado de la madre de Ted, ya que en un restaurante no se alzan las manos de esa forma. Por tanto la marca que nos muestra el humor es la marca kinésica gesto. La risa viene provocada por la caída que sufre la camarera tras la acción de la madre de Ted, siendo la camarera el blanco de la burla.

Además, hemos encontrado un caso (14) en la segunda parte del capítulo 9 donde el humor visual se genera junto a la marca kinésica de manera, siendo esta una reacción exagerada. La trama de este episodio gira en torno al secreto que guarda Robin relacionado con la fobia que siente hacia los centros comerciales. Lily y Marshall se acaban de enterar que Barney va a recibir vía Internet el video donde aparece el origen de esta fobia. Por otra parte, Ted y Robin están en el salón de la casa de Ted, hablando sobre los secretos. Robin le acaba de pedir a Ted que no le obligue a revelar su secreto, en ese momento los otros personajes entran corriendo de manera precipitada en el salón donde se encuentran Ted y Robin.

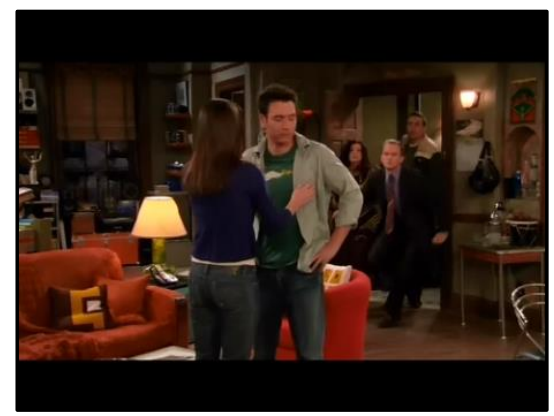

IMAGEN 17: Barney, Lily y Marshall entrando precipitadamente en el salón

En esta ocasión (14) la oposición de guiones que crea el efecto hilarante es reacción adecuada / reacción exagerada, ya que no pueden esperar ni un minuto para conocer el secreto inconfesable de Robin. De ahí que el mecanismo lógico sea la imagen y la marca utilizada la marca kinésica manera. 
Otra escena (15) que mezcla estos elementos y además la marca kinésica gesto la encontramos en la primera parte del capítulo 16. Lily invita a sus amigos a una obra de teatro donde ella participa. Mientras están viendo dicha obra, Barney saca una bolsa y hace como si vomitase.

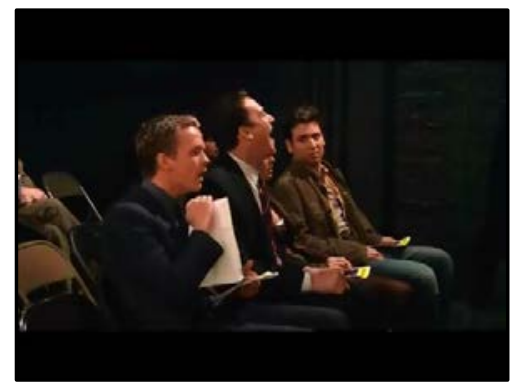

IMAGEN 18: Barney vomitando

En (15) la oposición de guiones es comportamiento adecuado / inadecuado, encontramos el mecanismo lógico a través de la imagen a partir de varias marcas. Por un lado, mediante la marca kinésica gesto de vomitar que realiza el personaje; y por otro, a través de la marca kinésica manera, puesto que no es un comportamiento adecuado. En una situación como la que nos presenta la escena, lo que se espera es una reacción de empatía, a pesar de que la obra no te agrade. Además, toda la escena en sí es una reacción exagerada por parte del personaje. En este caso, el blanco de la burla es la obra de Lily.

Por otro lado, encontramos un caso, (16), que siempre produce risa en el espectador. Se trata de la caída de algún personaje, como en la segunda parte del capítulo 15 cuando Ted va andando rápido por el aeropuerto y tropieza.

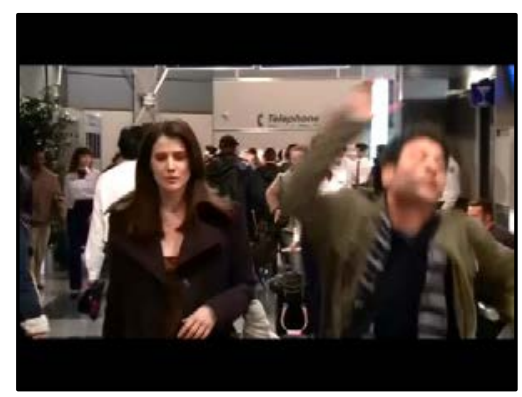

IMAGEN 19: Ted cayéndose en el aeropuerto

En (16) la oposición de guiones es correr / caerse y el mecanismo lógico lo encontramos en la acción que nos muestra la imagen. Como ocurría en el ejemplo (13) la risa aparece cuando vemos al personaje en el suelo tras un tropiezo. En este caso la marca utilizada es la que hemos denominado marca kinésica caída y el blanco de la burla Ted. 
Para finalizar, entre los casos que mezclan la imagen con alguna marca kinésica, encontramos uno, (17), en la primera parte del capítulo 7, cuando Ted le dice a Marshall una técnica que utiliza para ligar y Marshall intenta imitarle.

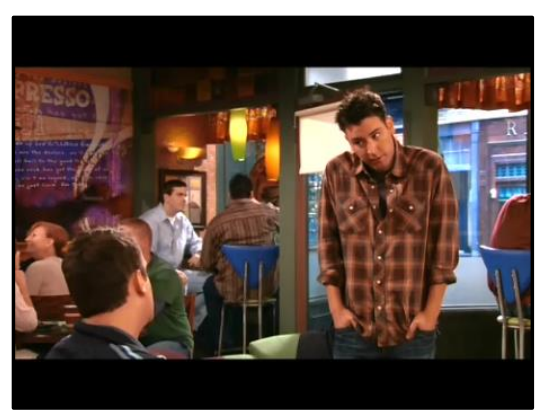

IMAGEN 20: Postura que recomienda Ted a Marshall

(21)

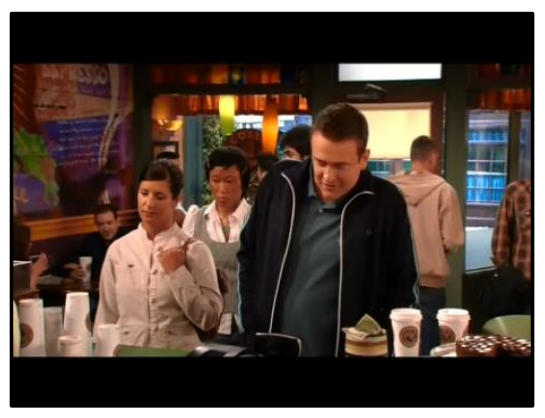

IMAGEN 21: Marshall realizando la postura que le recomienda Ted

En (17) la oposición de guiones es seductor / ridículo, el mecanismo lógico se produce a partir de la imagen, donde la marca utilizada es la marca visual comparación de imágenes. Primero vemos a Ted realizando un ritual que nunca falla a la hora de pedirle una cita a alguna chica (cabeza abajo, ojos hacia arriba, manos en los bolsillos, hombros levantados, cabeza inclinada para dar sensación de vulnerabilidad). Posteriormente, la comicidad aparece al ver los gestos y posturas extraños que realiza Marshall, siendo este último el blanco de la burla.

Por tanto, en cuanto al humor visual donde la kinésica de los personajes crea la incongruencia, podemos señalar que las marcas utilizadas son: marca visual tanto imagen como comparación de imagen; marca kinésica gesto, ya sea facial o corporal; marca kinésica postura; marca kinésica caída; $y$, marca kinésica manera, donde encontramos un comportamiento no adecuado ante la situación social en la que se inserta el humor o una reacción exagerada por parte de los personajes.

En el siguiente apartado analizaremos el humor visual que se consigue tanto a través de la actuación de los personajes como de su carácter. 


\subsection{Humor visual a través tanto de la actuación de los personajes como de su carácter}

En las siguientes líneas observaremos dos casos donde el humor visual aparece mezclando tanto la actuación de los personajes como su forma de ser. Nos parece conveniente señalar que para entender este tipo de humor es necesario conocer los rasgos característicos de los personajes. Ambos ejemplos se han encontrado en la primera parte de los capítulos y a través del mismo personaje, Barney. No hemos encontrado ningún caso en las demás partes de los distintos capítulos analizados.

En (18), primera parte del capítulo 1, aparece Barney en una mesa del bar dialogando con Ted y Robin, en medio de la conversación Ted y Robin no pueden evitar darse muestras de amor, Barney reacciona como vemos en la imagen 22.

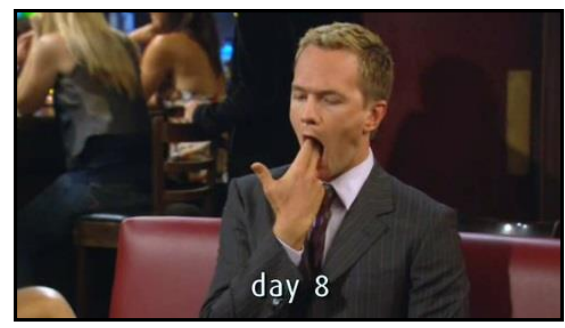

IMAGEN 22: Barney pegándose un tiro

En este caso la oposición de guiones es comportamiento adecuado / inadecuado. El mecanismo lógico aparece por medio de la imagen, por un lado a través de la marca kinésica gesto que realiza el personaje, ya que las normas sociales establecen unos comportamientos dentro del entorno de la conversación, que Barney contradice con su gesto. Además, en este caso también encontramos la marca idiosincrásica, ya que se trata de un rasgo del personaje, puesto que este se caracteriza por estar en contra de mantener una relación amorosa seria. En este caso los blancos de la burla son Ted y Robin.

El siguiente ejemplo, (19), lo encontramos en la primera parte del capítulo 20. En este caso se encuentran todos los personajes en el bar excepto Barney, de repente vemos a dicho personaje dentro del bar montado en bicicleta.

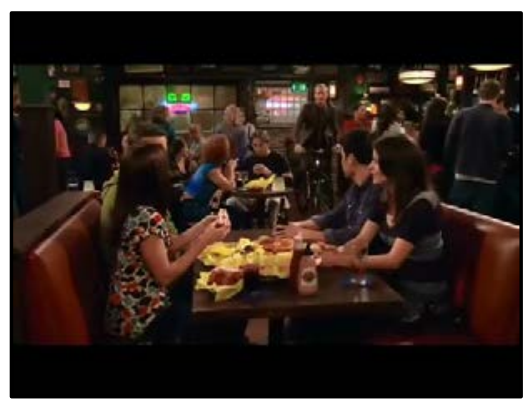

IMAGEN 23: Barney entrando al bar en bicicleta 
La oposición de guiones es comportamiento adecuado / inadecuado. El mecanismo lógico lo encontramos a través de la imagen por dos motivos: en primer lugar, junto a la marca kinésica de manera, ya que entrar en un bar montado en bicicleta es un comportamiento inadecuado; $y$, en segundo lugar, junto a la marca idiosincrásica donde apreciamos un rasgo característico de Barney, porque se trata de un personaje que no practica ningún deporte y además siempre va vestido con traje.

Tras los dos ejemplos analizados, podemos afirmar que las marcas que muestran este tipo de broma visual son cuatro: marca visual imagen, marca kinésica gesto, marca kinésica manera y marca idiosincrásica.

Una vez comentados los casos de humor visual a partir de una imagen incongruente, de humor visual donde la kinésica de los personajes crea la incongruencia y de humor visual a través tanto de la actuación de los personajes como de su carácter, pasaremos a examinar dos casos especiales que recuerdan a una escena del cine mudo clásico.

\subsection{Casos especiales: cine mudo}

Por último, para terminar con el análisis del humor visual de la segunda temporada de Como conocí a vuestra madre, prestaremos atención a dos casos especiales que simulan el cine mudo clásico donde se desarrolla una escena sin diálogo, simplemente a través de una sucesión de imágenes. Encontramos un caso en la primera parte y el otro en la cola. No hemos encontrado ningún caso en las otras partes de los diferentes capítulos.

El primer ejemplo, (20), se encuentra en la primera parte del capítulo 15. Barney acaba de correr la maratón de Nueva York sin haber entrenado antes. Ese día, el metro es gratis para los corredores y Barney decide probar ese medio de transporte, ya que nunca lo ha utilizado. La escena comienza con el personaje sentado en el metro. Cuando llega a su parada se levanta, pero se cae. No se puede levantar porque sus piernas se han quedado sin fuerzas después de la carrera. Finalmente se levanta con ayuda de los brazos y se coloca las piernas.

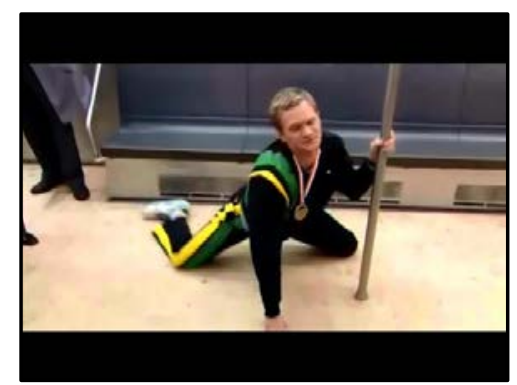

IMAGEN 24: Barney intentándose levantar

En (20) la oposición de guiones es levantarse / caerse y el mecanismo lógico lo encontramos por medio de la imagen, primero la risa aparece a través de la marca kinésica caída cuando el personaje se cae, posteriormente por medio de la imagen al ver 
las dificultades que está pasando Barney para poder levantarse porque no le reaccionan las piernas. El blanco de la broma es el personaje protagonista de la escena. Se trata de una escena que simula el cine mudo clásico.

La siguiente escena (21) la encontramos en el mismo capítulo que el caso anterior. Vemos que Barney continúa en el metro porque todavía no se ha podido levantar después de haber corrido la maratón de Nueva York. Se le acercan unos matones, se sientan a su lado y le miran la medalla que acaba de ganar. Ante esta situación, Barney les entrega la medalla y los matones se van.

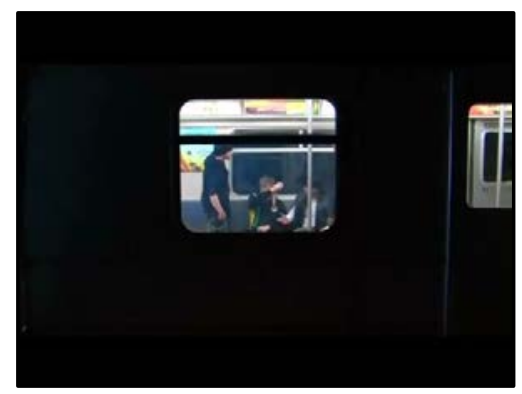

IMAGEN 25: Barney entregándoles la medalla a los atracadores.

En (21) la oposición de guiones es defenderse / resignarse y el mecanismo lógico viene motivado por la imagen. Como en el caso anterior, recuerda al cine mudo cómico, ya que no hay ningún sonido, y vemos cómo Barney, resignado, tiene que entregar a los matones la medalla que ha ganado. Por tanto, se utiliza la marca visual imagen. La broma se cierra con la marca kinésica gesto, concretamente el gesto de resignación que realiza el personaje al final de la escena, como muestra la imagen 26.

(26)

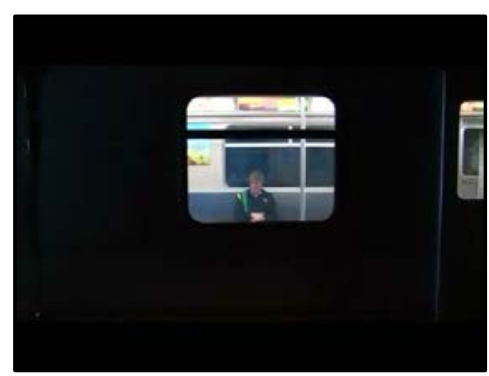

IMAGEN 26: Barney resignado después de que le hayan robado la medalla

Después del análisis realizado podemos señalar que el humor visual de la comedia de situación estadounidense Cómo conocí a vuestra madre se consigue a través de elementos extralingüísticos. Las marcas encontradas son marcas visuales, donde la imagen es el elemento principal para crear el efecto cómico, junto a marcas kinésicas como son gestos, maneras, posturas y caídas; y marcas idiosincrásicas como rasgos característicos del personaje. 


\section{Conclusiones}

El objetivo marcado para este estudio ha sido examinar los mecanismos humorísticos que se utilizan para crear bromas visuales dentro de un género humorístico, como es la comedia de situación estadounidense, concretamente hemos analizado la segunda temporada de la sitcom Cómo conocí a vuestra madre. Con ello, pretendemos obtener un patrón generalizable que se pueda extrapolar a otras temporadas de dicha serie y a otras series dentro de este género.

Para ello, hemos analizado un corpus con 23 ejemplos de humor visual que no contiene ningún elemento lingüístico ni sonoro. En estos casos, el efecto humorístico se consigue a través de tres vías: a) humor visual a partir de una imagen incongruente, b) humor visual donde la kinésica de los personajes crea la incongruencia, y c) humor visual a través tanto de la actuación de los personajes como de su carácter.

Tras el análisis efectuado, podemos afirmar que el humor visual, a través de la imagen, es un recurso poco utilizado y siempre orientado a hacer reír al espectador. No se utiliza en todos los episodios, aunque lo hallamos en las diferentes partes de las que se compone un capítulo (avance, primera, segunda, tercera y cola), siendo la segunda parte la que cuenta con más casos.

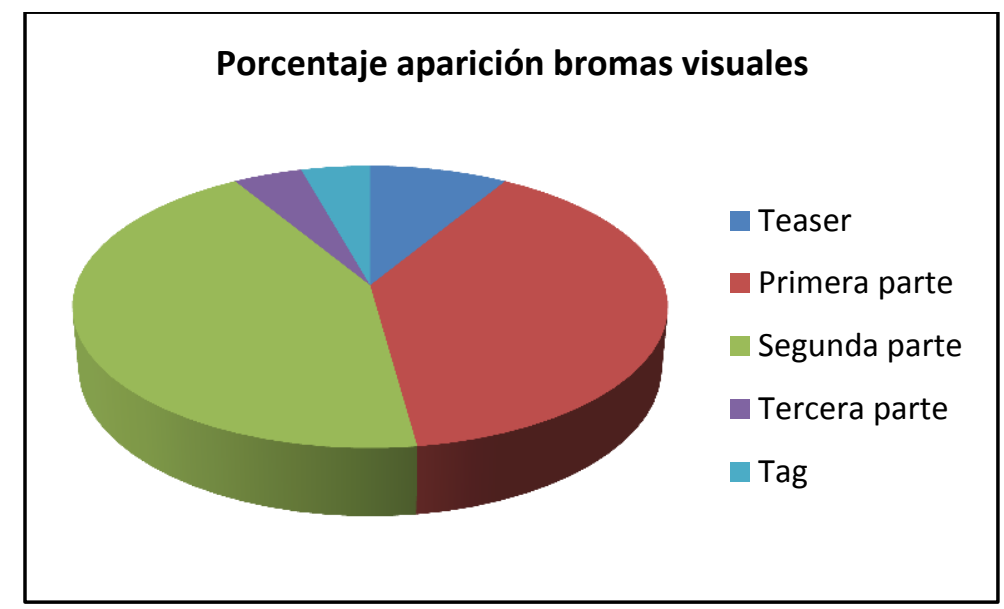

FIGURA 6: Porcentaje de parición bromas visuales en las diferentes partes de los capítulos

Nos hemos apoyado en la Teoría General del Humor Verbal (TGHV) establecida por Attardo y Raskin en 1991. Esta teoría explica el humor a partir de seis recursos de conocimiento: oposición de guiones, mecanismo lógico, situación, meta, estrategia narrativa y lenguaje. Sin embargo, hemos tenido que modificar este último recurso, puesto que no se trata de un lenguaje verbal, sino visual.

Los mecanismos utilizados para crear el efecto hilarante en el humor visual son elementos extralingüísticos, que no necesitan el lenguaje, y se apoyan en la imagen. En 
los casos que hemos encontrado donde el efecto cómico aparecía a través exclusivamente de la imagen, aparecen distintas marcas. En primer lugar, en el humor visual a partir de una imagen incongruente, la marca que se ha utilizado es la marca visual imagen. Esta se ha utilizado de tres formas diferentes: por un lado como imagen en sí misma, en estos casos la imagen es la que crea comicidad puesto que es incongruente con los demás elementos de la escena. Por otro lado, la imagen como ruptura de expectativas, donde el contexto lleva al espectador a formarse una idea de lo que pasará a continuación, sin embargo, a través de la imagen dicha idea no se desarrolla y es lo que crea el efecto cómico. Por último, también encontramos humor a través de la acción que muestra la imagen y que se desarrolla sin ningún soporte sonoro ni lingüístico. En segundo lugar, en el humor visual donde la kinésica de los personajes crea la incongruencia, hemos hallado marcas como gestos faciales o corporales, concretamente a través de las manos, la caída de algún personaje, un comportamiento no adecuado, una reacción exagerada o una postura extraña. En tercer y último lugar, en el humor visual a través tanto de la actuación de los personajes como de su carácter, se han utilizado la marca kinésica facial y corporal, la marca kinésica manera, la marca visual imagen y la marca idiosincrásica, esto es, en estos casos la imagen se complementa con los gestos, ya sea de las manos o de la cara, un comportamiento no adecuado, una reacción exagerada y un rasgo característico del personaje que realiza la escena que causa el efecto humorístico.

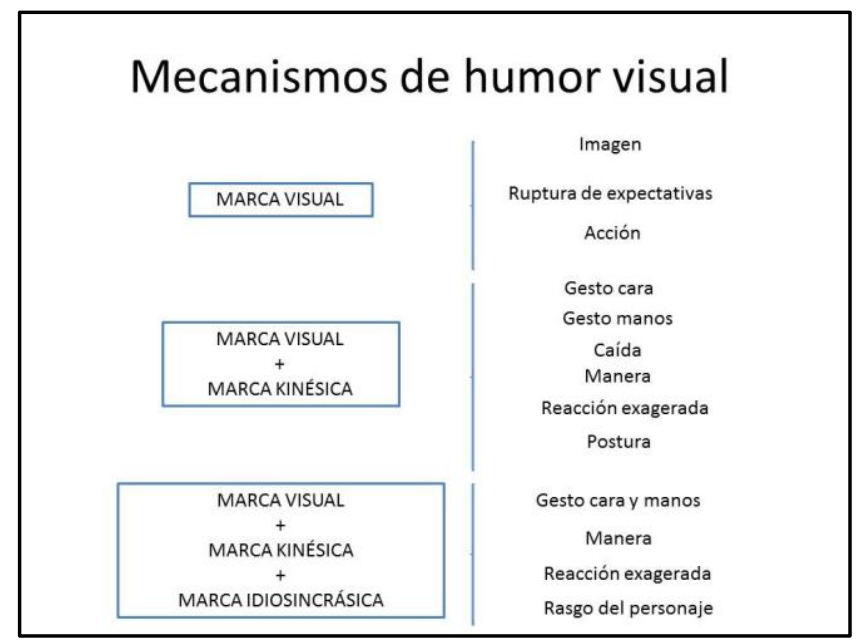

FIGURA 7: Cuadro-resumen de mecanismos que crean humor a partir de la imagen

Para terminar, nos parece conveniente señalar que este artículo es un esbozo de una parte de la tesis que estamos realizando, donde se analizan los mecanismos humorísticos que se utilizan para producir humor en las comedias de situación. Este género se caracteriza por mezclar en las escenas tanto humor verbal como situacional y visual. De este modo, se consigue que el espectador ría en periodos de tiempo reducido. Para ello se estudian dos sitcoms, una estadounidense y otra española. Nuestra tesis 
posee un doble objetivo: por un lado, pretendemos establecer un parámetro generalizable de los mecanismos humorísticos que utilizan las comedias de situación, que se pueda extrapolar a otras obras de este género. $Y$, por otro, pretendemos poder enseñar estos mecanismos en la clase de ELE, puesto que pensamos que el humor es un aspecto muy importante a la hora de aprender una lengua.

Recibido: 15.01.2014

Aceptado: 22.07.2014

\section{Referencias bibliográficas}

Aliaga Aguza, L. (2013): «Acercamiento pragmático al humor verbal en el género audiovisual: la serie de situación Cómo conocí a vuestra madre». En Alvarado Ortega y Ruiz Gurillo (Coords.): Humor, Ironía y Géneros Textuales. Alicante, Servicio de Publicaciones de la Universidad de Alicante.

Alvarado Ortega, B. y Ruiz Gurillo (Coords.) (2013): Humor, Ironía y Géneros Textuales. Alicante, Servicio de Publicaciones de la Universidad de Alicante.

Álvarez Berciano, R. (1999): La comedia enlatada: de Lucille Ball a Los Simpson. Barcelona, Gedisa.

Attardo, S. (1994): Linguistic Theories of Humor. Berlin, Mouton de Gruyter.

Attardo, S. (2001): Humorous Texts: A Semantic and Pragmatic Analysis. Berlin, Mounton de Gruyter.

Attardo, S. (2008): «A primer for the linguistics of humor». En Raskin, V. (ed): The Primer of Humor Research. Berlin, Mouton de Gruyter, págs. 101-155.

Attardo, S. y Raskin, V. (1991): «Script theory revis(it)ed: Joke similarity and joke representation model», Humor, 4 (3-4), págs. 293-347.

Bonet Mojica, L. (2003): El cine cómico mudo un caso poco hablado (Chaplin, Keaton y otros reyes del gag). Madrid, T\&B editores.

Cestero Mancera, A. M. (2006): «La comunicación no verbal y el estudio de su incidencia en fenómenos discursivos como la ironía», ELUA, 20, págs. 57-77.

Cuéllar, C. (1998): «El mecanismo mágico: definición y descripción del 'gag' cinematográfico», Semiosfera, 8 , págs. $65-88$.

DRAE, 22 Edición, versión on - line, www.rae.es (23-02-13)

Gómez Capuz, J. (2002). «Mecanismo del lenguaje humorístico (con especial atención al nivel pragmático)», Oralia, 5, pp. 75-101.

Grandío Pérez, Ma M y Diego González, P. (2009): «La influencia de la sitcom americana en la producción de comedias televisivas en España. El caso de 'Friends' y '7 Vidas'», Ámbitos, 18 - Año 2009, págs. 83 - 97.

Martín Peña, F. (1991): La comedia en el cine, 1895 - 1930. Madrid, Editorial Catriel.

Poyatos, F. (1994): La comunicación no verbal 1: Cultura, lenguaje y conversación. Madrid, Biblioteca Española de Lingüística y Filología Istmo. 
Poyatos, F (2003): «La comunicación no verbal: algunas de sus perspectivas de estudio e investigación», Revista de Investigación Lingüística, 2, vol. IV, págs. 67 - 83.

Raskin, V. (1985): Semantic Mechanisms of Humor. Reidel, Dordrecht.

Raskin, V. (ed.) (2008): The Primer of Humor Research. Berlin, Mouton de Gruyter.

Ruiz Gurillo, L. (2012): La lingüística del humor en español. Madrid, Arco Libros.

Ruiz Gurillo, L. y Alvarado Ortega, M. B. (eds.) (2013): Irony and Humor. From pragmatics to discourse. Ámsterdam, John Benjamins.

Ruiz Gurillo, L. y Padilla García, X. (2009): Dime cómo ironizas y te dire quién eres: una aproximación pragmatica a la ironía. Frankfurt, Peter Lang. 